\title{
A "verdade" no fim da estrada - uma análise do romance tudo se ilumina, de Jonathan Safran Foer, e de sua versão cinematográfica, do diretor Liev Schrieber
}

\section{The "truth" at the end of de road: an analysis of the romance everything is illuminated, by Jonathan Safran Foer, and their film versions by the director Liev Schrieber}

\begin{abstract}
Resumo: Este texto analisa o romance Tudo se Ilumina, de Jonathan Safran Foer, e sua versão cinematográfica, dirigida por Liev Shrieber, sob o ponto de vista da construção da "verdade narrativa". O romance apresenta três linhas narrativas distintas que revelam o universo interior dos personagens. Sua compreensão se dá a partir da conjunção destas três linhas, produzindo um significado totalizador da obra, revelando as motivações dos personagens e sua compreensão da vida. O próprio conceito de verdade - fatos $\mathrm{x}$ suas versões - é discutido no romance uma vez que seu processo de criação é exposto ao leitor. Investigamos como um romance com características marcadamente pós-modernas - entre elas o uso de diferentes pontos de vista para a narração e a discussão de questões metaficcionais - pôde ser adaptado para o cinema, e em que medida estes aspectos marcantes se perderam ou ganharam outras contações na grande tela.

Palavras-chave: Verdade; Narrativa; Pós-modernismo; Foer; Shrieber; Tudo se Ilumina

Abstract: This article analyzes the novel Everything is Illuminated, by Jonathan Safran Foer, and its film version directed by Liev Schrieber, focusing on the construction of a "narrative truth". The novel develops in three distinct lines that reveal the inner-self of the characters. Its full understanding is only possible when we analyze these three lines altogether, once they can produce the meaning of the narrative, unveiling characters' motivations and understanding of life. The very idea of "truth" - facts versus their versions - is at stake as the novel's creation process is exposed. The article tries to understand how it was possible for a novel so deeply marked by post-modern features - like the use of different narrative points of view and the discussion of metafictional aspects - could be transformed into a film, and to what extent these aspects are lost or gained new forms when transported to the big screen.

Key words: Truth; Narrative; Post-modernism; Foer; Schrieber; Everything is Illuminated.
\end{abstract}

Mestre em Literatura - Universidade Federal do Paraná. E-mail: jefferro@ uol.com.br 
Jeferson Ferro

O sucesso de público e crítica conquistado pelo jovem escritor norte-americano Jonathan Safran Foer com seu primeiro romance, Everything is Illuminated (2003), o que levou um crítico do The Times a afirmar "after it, things will never be the same again", coloca-nos já de início uma questão primordial: o que há de novo neste romance? A sua subsequente versão cinematográfica, intitulada como o original - que em língua portuguesa ficou "Uma vida iluminada" (Warner Independent Pictures, 2005) - ainda que tímida se comparada à atenção conquistada pelo livro, realizada por um diretor estreante, Liev Schreiber, que também assina o roteiro, e estrelada por Elijah Wood, acrescenta mais um questionamento interessante à análise da obra: se há algo de novo no romance, que efeito isto tem sobre sua transposição para a linguagem do cinema? Em outras palavras, se as fronteiras da narrativa literária foram de alguma forma estremecidas por "Tudo se ilumina", o mesmo teria acontecido com a narrativa cinematográfica derivada do texto?

Romance multifacetado, com três linhas narrativas distintas, "Tudo se ilumina" apresenta de forma marcante características consideradas típicas do universo pós-moderno. As categorias de autor-narrador-personagem são embaralhadas - Foer é o autor do livro, mas também protagonista e narrador da história, papéis estes que divide ainda com Alex - e, se formos um pouco além do texto propriamente e lermos algo a respeito do autor em carne e osso, descobriremos que ele realmente fez uma viagem à Ucrânia, da mesma forma que o personagem que leva seu nome, e com a mesma intenção. Este "liquidificador polifônico" em que somos atirados desde o princípio da leitura do romance, confundindo os limites entre realidade e ficção, e da própria "verdade dentro da ficção", uma vez que entraremos em contato com versões conflitantes dos fatos ficcionalizados, caracteriza bem o estado de incerteza e insegurança em que vive o homem contemporâneo.

Neste sentido, a linguagem empregada pelo autor para contar a história a partir da narrativa de Alex é um elemento importante. O narrador da viagem de Jonathan à Ucrânia, na linha narrativa que abre o romance, é um jovem ucraniano que escreve com o auxílio de dicionários, fazendo escolhas vocabulares "ingênuas" - já que não domina bem a língua inglesa - e por isso hilárias, que compreendem mais do que um efeito meramente cômico. Por meio desta estratégia, Foer chama a atenção para o valor primitivo das palavras, resgatando sentidos que se apagaram pelo uso cotidiano da linguagem.

\footnotetext{
FOER, 2003. (Trad.: “depois disto, as coisas nunca mais serão as mesmas”) 
A "verdade" no fim da estrada - uma análise do romance Tudo se llumina, de Jonathan Safran...

Além de funcionar como uma metáfora do desgaste da linguagem de uma forma geral, ela reflete a perda da confiança no poder mimético da palavra: a verdade das coisas não está no léxico. Poderíamos deduzir então que não há verdade alguma?

Sabemos que o mundo ocidental contemporâneo abdicou do conceito de verdade absoluta, pois nem a religião, nem a ciência podem definir as coisas de forma incontestável, ou seja, são incapazes de nos oferecer um porto seguro (HALL, 2004). No contexto amplo deste processo de relativização das formas de conhecimento, a própria significação, o sentido das palavras e, consequentemente, de tudo o mais passa a ser volátil. Onde um dia houve certezas, hoje há apenas discurso. Na teoria da literatura, já chegamos inclusive a acreditar que o mundo nem sequer existia (COMPAGNON, 2003). Uma vez que qualquer ideia de unidade e completude passou a ser severamente questionada, resta-nos viver essa fragmentação assumindo-nos como seres incompletos, incertos de nossa identidade e lugar no mundo:

“...sob a condição pós-moderna, o 'mundo lá fora', o 'mundo real', adquire em grau cada vez maior os traços tradicionalmente reservados ao mundo ficcional da arte. O mundo 'lá fora' afigura-se ao indivíduo como um jogo, ou antes uma série de jogos finitos e episódicos, sem nenhuma sequência definida e com consequências que não vinculam necessariamente os jogos que se seguem; e um jogo em que o próprio mundo é um dos jogadores, em vez de o supremo legislador ou árbitro, e um jogador que, exatamente como os demais jogadores, mantém suas cartas junto ao peito e adora jogadas de surpresa." (BAUMAN, 1998, p.155-6).

A literatura vai certamente abarcar esta fragmentação do indivíduo. Porém, mais do que simplesmente representá-la, ela poderá oferecer-lhe alguma espécie de ordem. Os narradores de Tudo se ilumina irão expor suas estratégias para a construção da história que nos contam, convidando-nos a duvidar do que escrevem, lembrando-nos de que a verdade não está em frente aos nossos olhos. Todavia, isto não significa que não reste ainda um "desejo de verdade" por trás desta aparente indiferença com o real. Para entender melhor como este desejo se manifesta na obra de Foer, e consequentemente na sua versão fílmica, vamos investigar alguns aspectos relevantes para a construção das narrativas que compõem este romance, considerado paradigmático de nossa época, e assim procurar responder às perguntas aqui propostas. 
Jeferson Ferro

\section{A fragmentação da narrativa: autor, narrador, leitor - todos são personagens.}

Talvez fosse uma boa ideia se Jonathan Safran Foer, no início de Tudo se ilumina, anunciasse algo como: "Atenção, leitoras e leitores, esta história explodiu antes que vocês pudessem conhecê-la. Por gentileza, procurem juntar os pedaços ao longo das próximas 360 páginas". Pois a sensação que temos ao iniciar a leitura é a de que estamos em meio a um emaranhado de destroços literários.

Se o tom humorístico do primeiro capítulo, Abertura para o encerramento de uma jornada muito rígida (e a ironia deste título não é casual), narrado em primeira pessoa por Alex, nos mantém atentos e garante boas risadas logo de saída, e o caos se apresenta já no capítulo seguinte, intitulado $O$ começo do mundo frequentemente chega. Somos então transportados para 1791, numa narrativa em terceira pessoa que nos fala de personagens estranhas, com nomes estranhos, num lugar estranho, envoltas em acontecimentos também incomuns. Segue-se mais um capítulo em Trachimbrod, este vilarejo "estranho", e em seguida lemos uma carta de Alex para Jonathan (o mesmo cujo nome consta da capa do livro), comentando detalhes de uma expedição realizada por ele à Ucrânia em busca de Trachimbrod, um vilarejo judaico destruído pela invasão nazista durante a Segunda Guerra Mundial - e fazendo menção à narrativa de que tomamos conhecimento no primeiro capítulo.

Acrescente-se aos aspectos perturbadores das histórias que lemos neste romance o fato de os narradores não fazerem questão alguma de nos explicar de antemão algo sobre o que irão contar - ou seja, eles não preparam o leitor para a fragmentação da narrativa, não justificam suas escolhas ou tentam nos convencer de qualquer coisa - e nos encontramos longe, portanto, de qualquer possibilidade de "ilusão realista" mais evidente do que aquela que poderemos encontrar no simples desenrolar dos fatos. Neste momento, poderíamos nos perguntar se o custo desta fragmentação radical da narrativa não seria alto demais para o leitor comum. Sobretudo em se tratando de um romance de estreia - não conhecemos o autor, não sabemos se vale a pena tentar lê-lo apesar das dificuldades que nos são colocadas já de início. Estaria o leitor disposto a empreender um esforço extra para entender em que direção aquela história prosseguiria? Deixando de lado, por ora, as questões de verossimilhança, a mera sequência das narrativas, após os três primeiros capítulos, 
A "verdade" no fim da estrada - uma análise do romance Tudo se llumina, de Jonathan Safran...

ainda não está clara - o que oferece um risco considerável ao engajamento na leitura(JOUVE, 2005).

Em face das dificuldades de se capturar o fio da história no começo, o alto teor de comicidade depositado no primeiro capítulo cumpre um papel fundamental: o de impulsionar a leitura em seu início, dando um fôlego ao leitor para que atravesse a confusão das próximas páginas até alcançar alguma luz. É somente no quinto capítulo, "Prelúdio ao encontro com o herói, e depois o encontro com o herói" (p. 39), quando voltamos à narrativa de Alex, que as coisas começam finalmente a se encaixar. A esta altura do romance já devemos ser capazes de identificar os fragmentos, agora não mais totalmente dispersos, e entramos na linha condutora da história. Ou melhor, nas três linhas condutoras da história:

I. A narrativa de Alex, uma espécie de narrador-testemunha, o guia de Jonathan em sua viagem para a Ucrânia, que, com o auxílio de um dicionário e dos conselhos do "herói" da história, recebe a incumbência de narrar os acontecimentos da viagem. Porém, desde o princípio ele trairá sua função narrativa, não sendo capaz de resistir à tentação de fazer de si mesmo o herói de seu relato. Nesta passagem, lemos sua descrição do momento em que vai à estação de trem encontrar Jonathan:

"Quando nos encontramos, fiquei atônito com a aparência dele. É isto um americano? Pensei. E também, é isto um judeu? Ele era severamente baixo. Usava óculos e tinha cabelos diminutos que não eram repartidos em lugar algum, mas jaziam sobre sua cabeça feito um chapéu. (Se eu fosse como Papai, poderia até tê-lo apelidado de Chapa.) Não se parecia com os americanos que eu presenciava em revistas, com cabelos amarelos e músculos, nem com os judeus dos livros de história, sem cabelos e com ossos proeminentes. Não usava calça jeans, nem uniforme. Na verdade, ele não parecia nem um pouco especial. Fiquei subimpressionado ao máximo." (FOER, 2005, p. 45).

Comentários como este, depreciativos à imagem do herói, assim como outros, laudatórios, que Alex tece em seu próprio favor, flagrando seu desejo de parecer melhor do que é, serão frequentes no seu relato. Estes comentários serão também motivo de alguns desentendimentos entre Alex e Jonathan, do que tomaremos conhecimento por meio das cartas, na terceira linha narrativa da história, revelando que a "verdade" não é bem o que parece. Dois outros personagens acompanham os narradores na sua viagem: o avô de 
Jeferson Ferro

Alex, chamado Vovô, motorista da trupe, e a cadela Sammy, sua companheira inseparável. Por fim, ressaltamos as já mencionadas habilidades linguísticas de Alex, típicas de um aprendiz de idioma estrangeiro, evidentes nas suas escolhas vocabulares que, aliadas à sua sinceridade quase infantil, dão o tom dominante de comicidade ao relato.

II. A narrativa de Trachimbrod, de 1791 até 1942, seguindo as vidas de Brod, uma antepassada de Jonathan, nosso autor-narrador-personagem, e mais tarde a de seu avô, já durante a Segunda Guerra Mundial. Trata-se de um relato repleto de elementos mágicos, liberdade que o narrador se permite diante da impossibilidade de se conhecer os fatos: uma vez que Trachimbrod foi destruída e não se sabe de qualquer sobrevivente, exceto seu avô, Safran, que há alguns anos está morto e jamais falou de seu passado europeu, resta-lhe inventar o que poderia ter acontecido. Sobre o nascimento de sua tatatatataravó no rio Brod, que lhe daria nome, (um bebê recém-nascido aparece flutuando após a queda de uma carroça no rio, acidente do qual não houve sobreviventes outros além do próprio bebê, tampouco testemunhas) Jonathan escreve:

"Os Fumeiros de Ardisht [...] acreditavam que a mãe da mãe da mãe da minha tataravó era Trachim renascido. No momento do julgamento no outro mundo, quando seu corpo amolecido se apresentara diante do Guardião daqueles gloriosos Portões pontiagudos, algo dera errado. Havia assuntos pendentes. A alma não estava pronta para transcender, e fora enviada de volta, recebendo a chance de corrigir o mal causado por uma geração anterior. Isto, é claro, não faz sentido algum. Mas o que será que faz?” (FOER, 2005, p. 27)

Esta será apenas uma das versões sobre o nascimento de Brod, que veio ao mundo como fruto de um acidente, sem qualquer referência a sua possível "origem real". No relato de Jonathan, a vida de Brod, como também a de seus descendentes, não será menos mágica e envolta em mistério do que foi o seu nascimento no rio. E a pergunta que encerra esta passagem, "O que faz sentido?", deixa claro o compromisso ficcional do narrador. É como se ele nos dissesse: não estou aqui para lhe contar a verdade, caro leitor. Enquanto o relato de Alex é uma fonte de humor escancarado e às vezes até truculento, a história contada por Jonathan será repleta de magia e poeticidade, funcionando como um centro de refinamento estético no romance.

III. Na terceira linha narrativa, lemos cartas escritas por Alex para Jonathan, esclarecendo vários aspectos do romance que de outra forma não 
A "verdade" no fim da estrada - uma análise do romance Tudo se llumina, de Jonathan Safran...

conheceríamos. Incumbido por Jonathan de escrever um relato da viagem que haviam feito, Alex toma muito gosto pelo trabalho da escrita e, com o desenrolar da narrativa, abandona sua posição inicialmente tímida, de quem submete tudo o que escreve à apreciação do mestre, e passa a questionar suas decisões, argumentando inclusive contra as opções feitas por Jonathan na história que escreve sobre Trachimbrod, pois ele não apenas escreve a sua narrativa, mas também lê a do "herói". Aqui encontraremos uma arena de debate meta-ficcional onde Alex representará ora o papel do escritor, ora o papel do leitor. De certa forma, é como se tivéssemos um canal aberto com o autor do livro e assistíssemos aos bastidores da criação do romance. Na passagem que lemos a seguir, observamos a reação de Alex, manifestada de forma um tanto quanto ingênua, para com o material que lera (assim como nós, leitores) da história contada por Jonathan:

"Tenho uma pequena indagação acerca desta seção, que é: você sabe que muitos dos nomes que você explora não são nomes verdadeiros na Ucrânia? Yankel é um nome que eu já ouvi, assim como Hannah, mas o resto é muito estranho. Você inventou todos eles? Notei muitos percalços como este, preciso lhe informar. Você está sendo um escritor humorístico, ou um escritor desinformado?" (FOER, 2005, p. 37)

Claro que estas cartas funcionam, na mão do autor, como um instrumento para direcionar a nossa leitura, à medida que nos identificamos com Alex - pois frequentemente ficamos tão confusos e perplexos quanto ele ao ler a história de Trachimbrod. Como Alex reage, via de regra, com extrema honestidade ao que lê, ainda que sua própria escrita não seja tão honesta assim, somos facilmente capturados por sua aura de ingenuidade autêntica. Devemos ainda notar que os comentários de Alex não serão sempre a respeito daquilo que já lemos na história, mas também sobre capítulos que ainda virão, o que aumenta a confusão cronológica sobre o desenvolvimento da narrativa na mente do leitor.

Desta forma, as primeiras quarenta páginas do romance nos colocam a par do que está acontecendo: Jonathan, um jovem aspirante a escritor, judeu norte-americano, viaja para a Ucrânia a fim de investigar o passado de seus ancestrais, mais especificamente, para encontrar uma mulher, cujo nome possivelmente seria Augustine, a pessoa que teria salvo seu avô dos nazistas, ajudando-o a fugir para os EUA. Sua única pista é uma foto e o nome do vilarejo de onde veio seu avô: Trachimbrod. O desejo de Jonathan era escrever um livro 
Jeferson Ferro

a partir do que descobrisse em sua viagem. Lá ele encontra Alex, um jovem local, filho do dono de uma agência de viagens que atende especificamente a judeus expatriados em busca de seus antepassados e familiares, e que, por falar inglês, será seu guia.

No tempo presente da história, turista e guia trabalham na construção de suas narrativas. A de Jonathan é um relato mágico sobre a vida de seus antepassados em Trachimbrod que, mesmo sendo declaradamente "inventado", uma vez que ele não dispõe de documentos ou qualquer outro registro histórico dos acontecimentos, assume certo grau de proximidade com o mundo real, já que trata de pessoas que realmente existiram (o avô), ou ainda poderiam ter existido (Brod), no contexto de uma guerra de efeitos bastante reais. Alex, por sua vez, trabalha na narrativa da viagem que empreendeu como guia de Jonathan, a qual acaba se transformando numa espécie de romance de formação do próprio narrador. Por fim, lemos as cartas de Alex para Jonathan, em que podemos assistir à recepção da história de Jonathan por Alex e às discussões dos dois - nunca lemos cartas de Jonathan, apenas os comentários e respostas de Alex - sobre o desenvolvimento das narrativas. Assim, as cartas funcionam como uma espécie de making-of da história, revelando por vezes o que "realmente" teria acontecido, algo diferente do que é relatado na narrativa, ao mesmo tempo em que expressam o processo de amadurecimento emocional de Alex.

\section{Road Movie}

A versão cinematográfica de Schreiber se concentra na narrativa de Alex, fazendo da história um road movie. O caos polifônico tão característico do romance, portanto, não foi transportado para a tela, e a história nos chega de forma "limpa", linear. Todavia, o diretor soube como incorporar elementos das outras narrativas em seu enredo, de modo a não perder o sentido global do romance, sentido este que depende da intersecção das três linhas narrativas. Mas ele está também consciente de que é preciso fazer recortes para que o filme seja uma obra em si mesma. E são essas escolhas na construção de narrativa cinematográfica que nos interessam aqui.

O espectador sabe que Alex está escrevendo um livro, já que o filme se inicia com a imagem do narrador escrevendo em uma folha de papel: "Chapter 1...", e que portanto a história nos chega por meio de um grande 
A "verdade" no fim da estrada - uma análise do romance Tudo se llumina, de Jonathan Safran...

flash back. Do debate que Alex trava com Jonathan no romance, por meio das cartas que lhe escreve, fica apenas uma auto-reflexão de Alex, em voice over. Se no romance a confusão proposital entre autor, narrador e personagem, já que Jonathan Safran Foer "é" os três, pode levar o leitor a se perguntar "Mas isto tudo aconteceu de verdade?", no cinema esta questão da autoria se perde. Mas nem por isso o telespectador estará livre de, ao final, se questionar "se é verdade" aquilo a que assistiu, ou seja, se a verdade da narrativa é o que parece. Tanto no filme como no livro, o encontro da "verdade" através do confronto com o passado, a "iluminação" que Alex e Jonathan, sem saber, procuram, é o motivo da viagem que ambos realizam. São verdades peculiares a cada um, de fato, assim como a verdade que chegará ao leitor / espectador.

$\mathrm{Na}$ leitura de Compagnon sobre as reinterpretações do conceito de mimèsis pela crítica literária do século XX, encontramos fundamentos para entender como esta "iluminação da verdade" de que falamos dentro do romance está ligada à ideia de "aprendizado mimético" (COMPAGNON, 2003). A partir da perspectiva de que existe uma inteligência mimética inerente à arte da ficção, "um reconhecimento que sai do quadro da intriga para tornar-se o do espectador, o qual aprende, conclui, reconhece a forma inteligível da intriga", entendemos o processo pelo qual a unidade de sentido da obra se "ilumina", fruto da busca que os personagens-narradores empreendem pela "verdade". Eles deverão aprender que a verdade não resulta apenas de um ato arbitrário de escolha, e assim iluminam também o leitor quanto à "verdade" de suas narrativas, concretizando o nosso processo de aprendizado pela ficção. Segundo Compagnon:

"O aprendizado mimético está, pois, ligado ao reconhecimento que é construído na obra e experimentado pelo leitor. A narrativa, segundo Ricoeur, é nossa maneira de viver no mundo - representa nosso conhecimento prático do mundo e envolve um trabalho comunitário de construção de um mundo inteligível. A produção da intriga, ficcional ou histórica, é a própria forma do conhecimento humano distinto do conhecimento lógico-matemático, mais intuitivo, mais presunçoso, mais conjetural." (COMPAGNON, 2003, p. 131)

Antes de nos aprofundarmos na "iluminação da verdade" e seu significado enquanto aprendizado mimético no romance, o que faremos mais adiante, uma outra questão, esta comum a toda obra literária ou cinematográfica, pois é requisito para a "suspensão da descrença", terá que ser respondida: "mas tudo 
Jeferson Ferro

isso poderia acontecer de verdade"? A resposta a esta pergunta no filme terá que ser dada de maneira diferente do que se faria com relação ao romance. No cinema, que possui naturalmente um poder mimético maior, na medida em que o cenário ganha cores, os personagens "carne e ossos" e a sua trajetória uma trilha sonora, a narrativa adquire naturalmente dimensões que estão além do texto. Esquivar-se destas dimensões seria um erro que certamente comprometeria a obra de Schreiber. Neste sentido, a escolha de Elijah Wood, famoso por representar personagens pouco ortodoxos, se podemos assim dizer (como a criatura "Frodo", de Senhor dos Anéis), para representar o papel de Foer pode ter contribuído para transmitir ao personagem certa aura de magia, que no romance se concentra na narrativa de Jonathan sobre seus antepassados.

Na tela, a Ucrânia ganha também um peso mais forte do que tivera no texto. Como os personagens estão constantemente na estrada, seria difícil relegar o cenário a um plano secundário. $O$ belo trabalho de fotografia realizado no filme, ressaltando o amarelo e azul da bandeira ucraniana, ganha proeminência. Assim, testemunhamos o orgulho de Alex e Vovô pelas belas construções de Odessa, o choque cultural entre o jovem da capital e os trabalhadores do campo, e os resquícios da era do comunismo na forma de conjuntos habitacionais abandonados - vale a pena lembrar a cena: diante do prédio cercado de mato, com as janelas todas quebradas, Jonathan pergunta a Alex: "O que aconteceu?"; e ele responde, laconicamente: "Independência." Vale ainda ressaltar a trilha sonora, uma versão de pop-folk ucraniano, acrescentando mais um ingrediente à salada cultural pós-moderna que o filme de certa forma representa.

Um elemento da maior importância para a narrativa de Jonathan ganhou, no filme, forma surpreendente, e por isso mesmo merecedora de destaque. Trata-se da razão pela qual ele decide ficcionalizar seu passado. Jonathan é judeu, seu avô fugira de sua terra natal para não ser morto. Sua busca na Ucrânia é a forma concreta, porém triste, de resgatar seu passado. Melhor sucedida é sua busca literária, ou seja, a invenção de seu passado realizada na história de Brod e Trachimbrod:

“- Lembrar o quê? [...]

- O quê [...] não é tão importante quanto o fato de lembrarmos. É o ato de lembrar, o processo da lembrança, o reconhecimento do nosso passado... As lembranças são pequenas preces a Deus..." (FOER, 2005 p. 52) 
A "verdade" no fim da estrada - uma análise do romance Tudo se llumina, de Jonathan Safran...

Lembrar é importante porque significa permanecer. Se o desejo de permanecer é inerente a todo ser humano, é bastante aceitável que ele se manifeste de uma forma especialmente forte para um povo que teve que lutar contra seu extermínio. E como lembrar de algo que nunca se soube? É preciso inventar. Assim como Toni Morrison, que entende seu fazer literário como uma arqueologia da memória dos que não deixaram relatos de suas vidas (MORRISON, 1998) - no caso dela, os negros escravos norte-americanos Foer decidiu que era preciso inventar a história de seus antepassados, pois só assim eles teriam uma chance de permanecer.

Schrieber, por sua vez, caracterizou o personagem Foer como um colecionador obsessivo. Desde criança, ele carrega consigo pacotes plásticos onde coloca objetos dos mais variados que encontra em seu cotidiano, para depois guardá-los, devidamente rotulados, num grande painel. Este painel, imagem central no filme, é a forma concreta, visual, de entendermos esta preocupação com o passado, com o desejo de permanecer.

Atento a todos os elementos envolvidos na composição cinematográfica, Schreiber foi capaz de incorporar à sua narrativa um micro-panorama histórico da Ucrânia, representando os conflitos de identidade que se manifestam num país periférico, porém com uma forte identidade nacional, identidade esta que foi bastante abalada pelos acontecimentos históricos recentes. Sua opção por uma narrativa linear, contrária à fragmentação que encontramos no romance, revela um interesse maior pela contextualização da viagem do herói, sem contudo perder a motivação da busca que guia as vidas dos protagonistas.

\section{A verdade iluminada}

Ainda que o estranhamento provocado no leitor do romance, fruto da sua multiplicidade de vozes narrativas, seja em tese um elemento positivo, ele não poderia ser tão forte a ponto de demovê-lo da ideia de seguir adiante. Esta espécie de "terrorismo literário" explícito empregado por Foer, ao gosto das maquinações pós-modernas, não tem, portanto, um caráter niilista, uma vez que não nos libertará de procurar sentido. Ao contrário, ele nos impulsiona a tatear a superfície do texto em busca das costuras que, embora não aparentes, sentimos que devem estar lá. É com este impulso, pois, que a história busca nos conquistar. E aqui se revela um falso paradoxo: ao mesmo tempo em que 
Jeferson Ferro

o romance é construído de forma fragmentária, conduzido por narradores diferentes, confundindo as noções de tempo e espaço e inserindo elementos desestabilizadores, como a linguagem "dicionaresca" de Alex e o surrealismo da história de Trachimbrod, as narrativas caminharão para uma mesma unidade de sentido. Se o mundo de hoje muitas vezes é descrito como caótico e desprovido de sentido, e a arte tende a revelar esse caos e abstração, por outro lado ela sustenta uma ordem interna que é condição primordial para seu sucesso. Ou seja, a arte possui a:

“... capacidade de simplificar a desnorteante complexidade, selecionar um grupo finito de atos e personagens na infinda multiplicidade, reduzir o infinito caos da realidade a proporções intelectualmente manejáveis, compreensíveis e evidentemente lógicas, apresentar o contraditório fluxo de acontecimentos como um narrativa com um enredo interessante de se ler..." (BAUMAN, 2003, p. 156)

Foer vai fundo na representação do caos, e sua confiança no potencial de recepção pós-moderna de seu público sai vencedora. Pagamos o preço, empreendendo o esforço necessário para progredir pelas páginas iniciais, perdidos no caos de vozes narrativas desconexas entre histórias que nos tiram o chão, sem falar nas dificuldades de linguagem, e por isso merecemos a luz que o título promete. $\mathrm{O}$ desejo da verdade em nós, leitores e espectadores, caminha de mãos dadas com a narrativa. E este desejo está em busca do seu momento de concretização, que será, não por acaso, transformado na cena principal do filme. Para compreendermos a importância deste "momento", tão bem capturado por Schreiber, voltamos a Compagnon e sua releitura da mimèsis:

"O momento do reconhecimento é, pois, para o leitor ou o espectador, aquele no qual o projeto inteligível da história é apreendido retrospectivamente, aquele no qual a relação entre o início e o fim torna-se manifesta, precisamente quando o mythos [enredo] torna-se dianoia [o tema], forma unificante, verdade geral." (COMPAGNON, 2003, p. 129).

A concretização dos desejos de verdade de nossos narradores-personagens é o momento da iluminação, e representa ao mesmo tempo o encontro de Jonathan com o que procurava e a tomada de consciência de Alex de que ele pode "escolher" suas verdades, libertando-se assim do que o oprime, consciência esta que representa o turning point de sua jornada de amadurecimento. Numa cena de grande impacto visual, Schreiber captou a emoção do momento em que os viajantes encontram Trachimbrod, na forma de 
A "verdade" no fim da estrada - uma análise do romance Tudo se llumina, de Jonathan Safran...

sua última remanescente, a irmã de Augustine, a cena que define o "momento do reconhecimento" para os três viajantes, pois ela inclui ainda Vovô, que escondia um mistério que passará então a ser revelado. O "reconhecimento" acontece ao mesmo tempo dentro da história e fora dela, porque o é para o leitor/espectador, e foi assim narrado por Alex no romance:

"Tal como naquelas ocasiões com Papai, é limitado o número de vezes que você pode pronunciar 'Não dói' antes que a coisa comece a doer até mais do que a própria dor. Você fica iluminado com a sensação de sentir dor, o que é pior, estou certo, do que a dor existente. Não-verdades pendiam diante de mim como frutos. Qual eu colheria para o herói? Qual eu colheria para Vovô? Qual para mim mesmo?” (FOER, 2005, p.163).

Esta contundente compreensão da ligação que existe entre o real e o discursivo, a dor e o desejo de não senti-la, significa o reconhecimento de nossa incapacidade de nos esquivarmos da verdade fingindo que ela não existe. Próximo ao final de sua narrativa, Alex fará um pedido dramático para que Jonathan, enquanto revisor de seu texto, permita que a ficção crie uma imagem positiva da realidade: "Uma pessoa má é alguém que não lamenta suas más ações. Agora Vovô está morrendo por causa das ações dele. Eu imploro que você nos perdoe, e nos faça melhor do que somos. Faça-nos bons." (FOER, 2005, p. 196). Mais do que ingênuo, este pedido mostra a consciência que o rapaz alcançou de como as "verdades" se constroem discursivamente, uma consciência que ele adquiriu pelo seu limite. Para o leitor, a luz emerge dos encaixes que vão se produzindo entre os cortes de uma narrativa para outra, delineando um sentido que paira sobre o todo, assim como o tema da repetição que se torna verdade, e que, antes de chegar à consciência de Alex, estava na história de Brod: "[...] a vida de Brod é segredo para ela própria. Tal como Yankel, ela repete as coisas até elas virarem verdade, ou até não saber mais se elas são verdadeiras ou não.” (FOER, 2005, p. 121).

O que temos hoje, enquanto leitores, espectadores e narradores, é a consciência de nossa incapacidade de capturar uma verdade única. Não surpreende que a arte tenha se libertado do realismo em favor das "verdades possíveis". Nas palavras de Margaret Atwood, sobre o vencedor do prêmio Nobel de Literatura em 2006: "Pamuk nos dá aquilo que todos os romancistas nos dão em seus melhores momentos: a verdade. Não a verdade das estatísticas, mas a verdade da experiência humana em um determinado lugar e um determinado tempo." (ATWOOD, 2006). A literatura de hoje, assim como o 
Jeferson Ferro

cinema, parece estar consciente de que só a verdade da experiência humana pode chegar até nós. E é esta verdade que atrai Jonathan e Alex em suas buscas individuais, é esta luz que deverá chegar, de alguma forma, ao leitor. A verdade da arte, no entanto, não é a verdade científica, como nos lembra Compagnon, pois é fruto do aprendizado mimético. Ainda assim, resta-nos a esperança de que numa era em que a busca por sentido aparentemente perdeu seu valor, a ficção poderá ser capaz de desvendar os mecanismos que ocultam a verdade do mundo (BAUMAN, 1998).

A busca de Jonathan é uma procura pela sua identidade, pelo passado de sua família que foi apagado pela guerra. Na impossibilidade de se descobrir fatos, a invenção deste passado surge então como uma alternativa. A memória, ou melhor, as narrativas de memórias possíveis são um elemento mais atraente do que qualquer investigação arqueológica de verdade. Sobretudo, é preciso ter lembranças, ainda que "inventadas". Desta forma, Foer opta pela ficcionalização da consciência dos que não deixaram relatos como uma forma legítima, e sobretudo necessária, de encontrar a verdade. A arqueologia ficcional, então, passa a ser a "ciência" do narrador. Não é por acaso que sua viagem está ancorada na foto de Augustine, um objeto feito de memória. Também não é por acaso que a caminhada de Jonathan, bem como sua narrativa, culminam no momento crucial da guerra, quando a morte toma conta da cena. Acontecimento traumático, e por isso permanente nas memórias de gerações futuras, a guerra representa o peso da dor que marca as vidas de tantas pessoas, um fato colocado acima do nível discursivo, mas que não foge ao nosso impulso narrativo: precisamos contar esta história para poder compreendê-la. No filme de Schreiber, mais uma vez o poder da imagem foi utilizado com maestria: do rio Brod, em cujos bancos estão enterrados tudo o que sobrou de Trachimbrod, emergem as vozes de seus antigos habitantes, e pessoas que um dia existiram agora são um número numa placa de bronze cravada no chão: "Este monumento foi erguido em memória dos 1.204 habitantes de Trachimbrod mortos pelas mãos do fascismo alemão em 18 de março de 1942. Inaugurado em 18 de março de 1992. Yitzhak Shamir, Primeiro-Ministro de Estado de Israel".

Alex, por sua vez, parece ter atingido a consciência de que a escrita pode ser às vezes tão forte quanto a realidade e que, mais importante, ela é um instrumento de relacionamento com a verdade. Ao se envolver na busca de Jonathan e também na construção da narrativa, ele ganha uma compreensão de sua própria realidade que jamais tivera. O que é verdade, o que é discurso? Que versão vamos escolher? Afinal, como construímos a ideia de quem 
A "verdade" no fim da estrada - uma análise do romance Tudo se llumina, de Jonathan Safran...

somos? Até onde podemos enganar a dor? À medida que ganha o controle de sua narrativa, Alex estará certamente mais apto a responder a perguntas como estas, como observamos neste trecho de uma carta para Jonathan:

\begin{abstract}
"Ao escrever, recebemos segundas chances. Na primeira noite da nossa viagem, você mencionou que achava que talvez houvesse nascido para ser escritor. Que coisa terrível, acho eu. Mas preciso dizer, acho que você não compreende o significado do que disse quando disse aquilo. Você estava fazendo sugestões de que gosta de escrever, e que para você é interessante imaginar mundos que não são exatamente como este, ou mundos que são exatamente como este. É verdade, tenho certeza que você escreverá muito mais livros do que eu, mas sou eu, não você, que nasceu para ser escritor." (FOER, 2005, p. 194)
\end{abstract}

Podemos ler a obra de Foer como uma investigação profunda de nosso desejo de verdade, falsamente perdido. Tudo se ilumina é um romance que nos diz que somos fragmentos, sim, mas não deixamos de procurar a unidade. Por mais forte que tenha sido o impacto destrutivo da guerra, que desmanchou no ar tudo o que era sólido, não há como fugir definitivamente do poder gravitacional da verdade. A jornada de Jonathan acontece porque seu avô está morto. Sua narrativa é, assim, uma busca pela história do homem que sobreviveu para que ele pudesse nascer, um resgate, portanto, de uma "épica da verdade" particular. Sua jornada chega ao fim quando encontramos outra morte, a do avô de Alex, que havia revelado a sua própria verdade ao final da viagem: o último capítulo do romance é uma carta de Vovô comunicando seu suicídio.

Na versão de Schreiber, Vovô também morre no final, e sua morte tem um papel libertador para Alex. Porém, a história não acaba aí. A cena seguinte é a de Jonathan chegando ao aeroporto de sua cidade, nos EUA. Ao passar pelos corredores, ele reconhece nas pessoas que estão ao seu redor rostos idênticos aos das pessoas que encontrara na Ucrânia - ou seja, trata-se dos mesmos atores. Mais do que transmitir uma conotação onírica à história, levando o espectador a suspeitar de que tudo aquilo não passou de um sonho, esta cena resgata o sentido fugidio da verdade, o que "é" e o que "parece ser". E então voltamos a uma cena inicial do filme, com Jonathan no cemitério, em frente ao túmulo de seu avô. Seu rosto agora é sereno, e ele despeja a terra que trouxera da margens do rio Brod sobre o túmulo, assim como Alex fará com seu avô, enterrado na Ucrânia. Se há sentido neste mundo, se é possível saber quem somos, é porque viemos de algum lugar, de alguém, e também porque 
Jeferson Ferro

podemos escolher nossos destinos, como Alex aprendeu.

Sem se aventurar no caos polifônico da obra de Foer, Schreiber conseguiu manter a unidade de sentido da obra em sua transposição fílmica. Conseguiu também explorar outras dimensões para sua narrativa, particulares à linguagem do cinema, perfeitamente compatíveis com o universo diegético do texto. Ainda que seu filme seja despretensioso e possa não angariar a atenção crítica que o romance conseguiu, foi bem sucedido e representa uma contribuição significativa à compreensão da obra de Foer.

Por fim, podemos entender que esta tendência da literatura contemporânea em se fragmentar, olhando para dentro de si própria, signifique mais do que uma manifestação da crise de identidade do homem pós-moderno. Ela pode ser a própria crise de identidade do discurso literário, sedento por recuperar uma especificidade que lhe parece perdida - até mesmo para o cinema. Seria então um "desejo da verdade literária", desejo de mostrar o que só a literatura é capaz de fazer, algo que não caberá dentro das fronteiras do cinema.

\section{Referências}

ATWOOD, Margaret. Um Nobel para nossa era. Folha de S. Paulo, 22/10/06.

BAUMAN, Zygmunt. Sobre a verdade, a ficção e a incerteza. In: O mal-estar da pós-modernidade. Rio de Janerio: Jorge Zahar Editor, 1998.

COMPAGNON, Antoine. O demônio da teoria: literatura e senso comum. Belo Horizonte: Editora UFMG, 2003.

FOER, Jonathan Safran. Tudo se Ilumina. Rio de Janeiro: Rocco, 2005.

HALL, Stuart. A identidade cultural na pós-modernidade. Rio de Janeiro: DP\&A, 2004. JOUVE, Vincent. A leitura. São Paulo: Unesp, 2005.

MORRISON, Toni. The site of memory. In: ZINSSER, William (Ed.). Inventing the truth: the art and craft of memoir. Boston: Houghton Mifflin Co., 1998. p.185-200.

UMA VIDA iluminada. Direção: Lieve Schrieber. Produção: Peter Saraf; Marc Turtletaub. Warner Independent Pictures, 2005. (106 min.).

Recebido para publicação em 05 jul. 2010

Aceito para publicação em 16 set. 2010 